\title{
The Beneficial Effects of Non-received Choice: A Study on Intrinsic Motivation in Biology Education
}

\author{
Annika Meyer ${ }^{1}$, Inga Meyer-Ahrens ${ }^{2}$ and Matthias Wilde ${ }^{1 *}$ \\ ${ }^{1}$ University of Bielefeld, Germany \\ ${ }^{2}$ University of Education Heidelberg, Germany \\ *E-mail: matthias.wilde@uni-bielefeld.de
}

\begin{abstract}
Previous research has found conflicting evidence in studies where students participate in the selection of their course topics in educational settings. Katz and Assor, for example, have argued that the increase in student motivation is probably not due to the mere act of choosing, but to the value of the options with respect to personal interest. The aim of our study was to investigate the impact of choice on aspects of motivation during biology lessons. Our sample consisted of five classes with 118 children of whom $63 \%$ were female. Their average age was 10.4 years $(\mathrm{SD}=0.6)$. One group of students was asked to select one topic out of four in a majority vote during a biology class, while a control group was simply assigned the same topic. Results: Students who chose their topic reported a higher level of intrinsic motivation than students who were not given the option. A surprising result was that the students in the voting group who did not receive their preferred choice reported the same level of motivation as those who did.
\end{abstract}

Keywords: choice, student vote, autonomy, intrinsic motivation

\section{Introduction}

Perceived self-determination or autonomy is regarded as beneficial to learning. According to SelfDetermination Theory (SDT; Deci \& Ryan, 2000) supporting student autonomy benefits their engagement in learning as well as their intrinsic motivation. Self-determination theorists assume that promoting a student's autonomy means promoting an internal locus of causality, a sense of volition as well as the perception of choice (Reeve, 2002). In other words, a student should perceive his or her behavior as initiated and regulated by a personal, and not by an environmental force. Further, the student should feel an unpressured willingness to engage in an activity, as well as to be able to choose among several options (Reeve, Nix, \& Hamm, 2003). Empirical findings on choice in educational settings remain ambiguous, at least to some extent (for an overview, see Katz and Assor, 2007). Reeve et al. (2003) suggested that internal locus and volition, but not perceived choice, constituted valid indicators of the experience of autonomy and of intrinsic motivation. They proposed that in studies where choice had increased intrinsic motivation, it might have had little to do with the experience of deciding between options, and more with an internal locus and a volitional sense of causality. These findings are relevant to science teachers, for instance, who may find themselves unable to accommodate each student's choice individually. Ultimately, should it be the case that choice alone can motivate 
students, it becomes less important to the teacher whether this benefit arises from having promoted an internal locus of causality and volition, or from the mere act of choosing itself. What matters is the positive end product.

However, given that in educational settings majority votes tend to be easier to implement, the response of students whose choice is not realized remains to be clarified. These students probably do not sense volition or an internal locus of causality. If it turns out that the mere act of choosing in fact does not have an impact on self-determination or intrinsic motivation, no benefits for these students should be expected. It is possible that a 'frustration effect' (Folger, Rosenfield, Grove, \& Corkran, 1979) can emerge, which can, in turn, result in a negative impact on motivation.Baldwins, Magjukas and Lohers' (1991) study on trainee motivation found precisely this effect. When trainees made a selection, but did not receive their choice, their motivation to learn declined significantly. Other findings suggest that the positive outcome of choice is dependent on the personal value of that choice, indicating that choosing itself may have no positive effect (Reeve et al., 2003; Assor, Kaplan, \& Roth, 2002). In this regard, our study has yielded some unexpected results. The goal of the present study was to investigate whether it was either the realization of the pupils' choice, or participation in a collective decision, that was responsible for the development of the pupils' intrinsic motivation.

\section{Theoretical Background}

In self-determination theory, autonomy is a core concept (Ryan \& Deci, 2006). The development of motivation requires the fulfillment of the pupils' need for autonomy (and competence). The importance of autonomy has been examined in hundreds of studies (Ryan \& Deci, 2006). Students who are autonomously motivated thrive in educational settings and benefit from their teachers support of their autonomy (Reeve, 2002). To clarify, autonomy refers to self-regulation (Ryan \& Deci, 2006). Autonomy is not the same as independence, and is not influenced externally (Krapp \& Ryan, 2002). People can feel autonomy even when they perceive external pressure to do something, if they wholeheartedly consent to an activity (Ryan \& Deci, 2006). Reeve et al. (2003) identified three qualities of autonomy: perceived locus of causality, volition and perceived choice. The perceived locus of causality reflects the perception of whether one's behavior is initiated by a personal (internal locus of causality) or an environmental (external perceived locus of causality) force (Reeve et al., 2003). Volition describes how free (or forced) people feel during an activity (Reeve et al., 2003). The third quality of autonomy is perceived choice. Perceived choice "emanates from being afforded decisionmaking flexibility and opportunities to choose what to do" (Reeve, 2002). Choice is meant to be able to enhance intrinsic motivation (Deci \& Ryan, 1985).

Research on choice has produced equivocal findings (Katz \& Assor, 2007). Ryan and Deci (2006) suggest that this may stem from the fact that choice has several meanings. For Ryan and Deci (2006), the feeling of choice refers to a sense of autonomy, and not necessarily to the presence of multiple options.It is possible to feel autonomous with only one option (indicating no choice), provided one endorses this option (Ryan \& Deci, 2006). Katz and Assor (2007) explain the inconsistencies using the missing integrative conceptual framework. This framework should be able to describe what makes a choice beneficial. They reviewed several studies about choice through the prism of SDTand found that choice was a motivating factor in the studies where the three basic psychological needs were satisfied, or at least not ignored (Katz \& Assor, 2007). To satisfy the need for autonomy Katz and Assor postulate that the options have to be relevant to the voter's interests and goals. As such, the effects of choice should be interpreted with caution because choice is often confounded by many other factors, i.e. interest (Reynolds \& Symons, 2001). In a meta-analysis of 41 studies, Patall, Cooper and Robinson (2008) examined the effect of choice on intrinsic motivation and related outcomes. Their results indicated a beneficial effect of choice, with the circumstances surrounding the choice influencing the effects (Patall, Cooper, \& Robinson, 2008). Not all types of choice enhance intrinsic motivation. 
Choices that support the need for autonomy appear to have a greater impact on motivation, performance and learning, for example. As such, the choice should reflect the values, goals or interests of the voter (Patall et al., 2008).

The goal of the current study was to investigate a choice-treatment with the potential to affect autonomy (e.g. Patall et al., 2008; Katz \& Assor, 2007).We designed our study to be maximally relevant to a "real-school-context" where classes of approximately thirty pupils are taught by a single teacher. We used a majority vote paradigm where students could vote on the topic for their next biology lessons. The students had four options, and all had positive connotations. Our study investigated the effect that a majority vote selection on subsequent lessons might have on motivation. We considered motivational differences between those students who received their selection, and those who did not.

\section{Hypotheses}

Since choice appears to support the basic needs of students, and in particular of autonomy, we propose that it has a positive effect on pupil motivation. The first hypothesis reads as follows:

H1: Pupils with the option to select the topic of their next biology lessons have higher intrinsic motivation than pupils without choice.

Presumably, the option to choose a topic can only serve to increase the motivation of an individual pupil when that topic is selected for teaching. In this case, the attractiveness of the topic alone should be responsible for the increase in intrinsic motivation, and not the act of choosing.

$\mathrm{H} 2$ : Pupils whose vote helped select the winning topic have higher intrinsic motivation than those who did not.

\section{Methods}

The participants were 118 children (63\% girls) from five classes. The average age was 10.4 years $(\mathrm{SD}=0.6)$. The fifth-grade pupils came from similar schools in the same region. The students were taught by graduate students who planned and practiced the lessons together. There were two conditions, a choice condition, and a no choice condition that served as the study's control. In the choice condition, three classes $(\mathrm{N}=73)$ participated in a majority vote to select one out of four biology topics. These were 'exercise and sports', 'injuries', 'healthy diet' and 'nutrition'. The chosen topic ('exercise and sports') was then taught as a sequence of four biology lessons. The four topics were presented in an unbiased manner by the student-teacher. At least two of the topics were thought to be of interest to pupils at this age.The attractiveness of various biological topics has been well researched in Germany (cf. for example: Löwe, 1992). The two remaining classes $(\mathrm{N}=45)$ were placed in the no choice condition and were simply assigned the same topic. Since a majority vote was taken, there were students in the choice condition that received their choice (choice received condition, $\mathrm{N}=30$ ) as well as students that did not (choice not received condition, $\mathrm{N}=43$ ), resulting in a total of three choice conditions. To compare the conditions (no choice, choice received, choice not received) with regard to their effect on intrinsic motivation, all students were asked to complete a translated, modified version of Deci and Ryan's (2010) Intrinsic Motivation Inventory (IMI). This modified version of the IMI consisted of four subscales: interest/enjoyment, perceived choice, perceived competence, and pressure/tension. Interest/enjoyment $(\alpha=.85)$, was used to assess intrinsic motivation per se. Perceived choice $(\alpha=.76)$ and perceived competence $(\alpha=.78)$ are positive predictors of intrinsic motivation. The subscale perceived choice should have been better named perceived autonomy since it is used to measure feelings of autonomy. Ryan and Deci (2006) define choice as a sense of volition or autonomy, and does not necessarily imply having many options. A sample item was, "I could work in the way I wanted to 
work". Pressure/tension ( $\alpha=.63$ ) is a negative predictor of intrinsic motivation. Validity (factor analyses and criterion validity) for this adaptation of the IMI was provided by Wilde, Bätz, Kovaleva and Urhahne (2009).

\section{Results}

We present results for all three conditions: pupils who (a) did not choose a topic (no choice), (b) those who chose and received their choice (choice received) and (c) those who chose but did not receive their preference (choice not received). The overall results of the multivariate ANOVA found no principal effect for gender on intrinsic motivation as well as no interaction between gender and condition, thus ruling out gender differences. However, overall results did show a significant effect of 'condition'in relation to the dependent variables interest/enjoyment $\left(F(2,109)=5.58, p<.01, \eta^{2}=0.1\right)$, perceived choice $\left(F(2,109)=3.91, \quad p<.05, \eta^{2}=0.07\right)$ and pressure/tension $\left(F(2,109)=3.49, p<.05, \eta^{2}=0.06\right)$. No difference was found for perceived competence $(F(2,109)=2.27, p=n s)$. Orthogonal contrasts between the conditions were conducted to further explore the nature of the observed differences. The first contrast compared the control group, namely the no choice condition, to the choice condition (regardless of whether choice was received or not). The results showed a significantly higher level of interest/enjoyment for the choice condition ( $C I: .546 \pm .327 ; \mathrm{p}<.01)$, as well as for perceived choice (CI: $.447 \pm .322, p<.01)$, and for perceived competence( $C I: .294 \pm .276, p<.01)$.Pressure/tension were found to be significantly lower $(C I: .311 \pm .307 ; p<.05)$. Of interest are the findings concerning the comparison between the choice received condition and the choice not received condition (second contrast). There was no difference between these two groups for any of the subscales: interest/enjoyment (CI:-

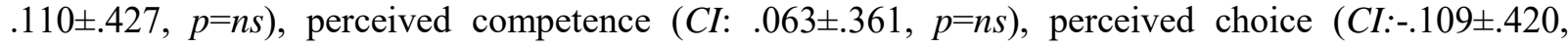
$p=n s)$, pressure/tension ( $C I: .356 \pm .402, p=n s)$.Figure 1 shows our findings.

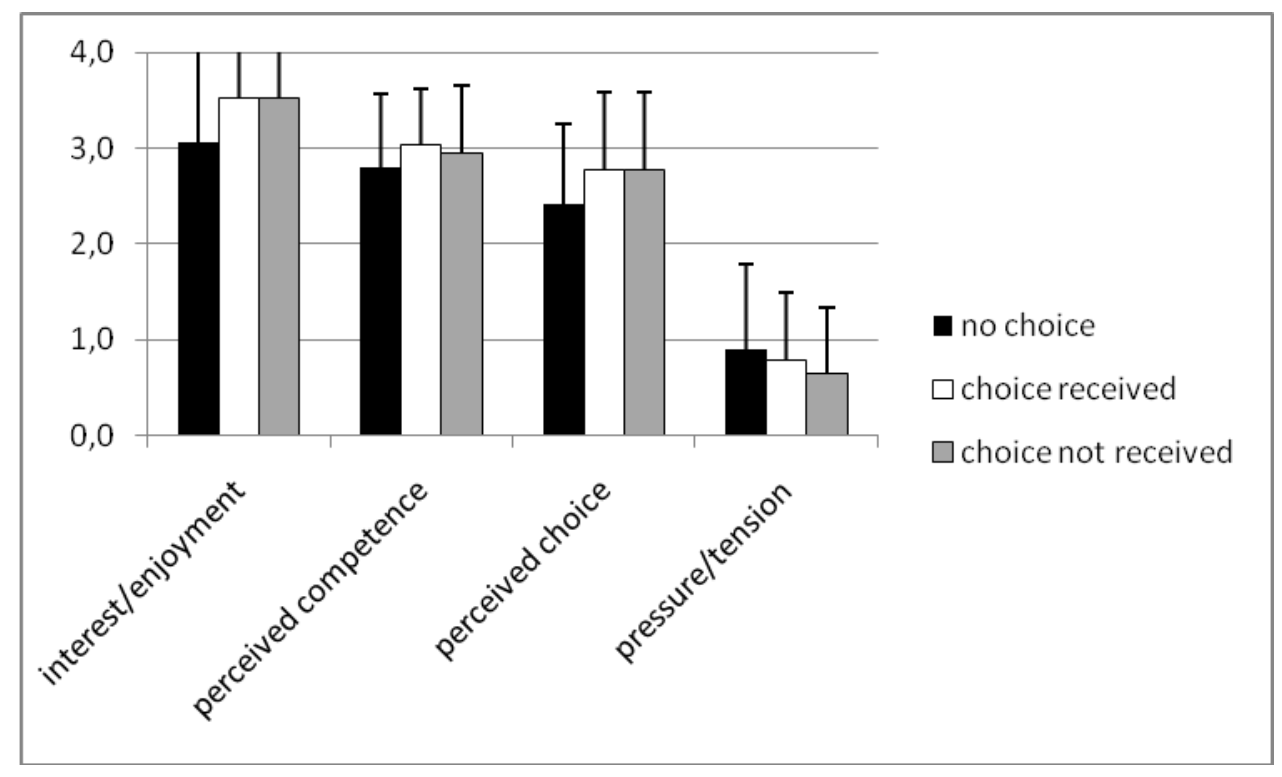

Figure 1. Results of the modified version of the Intrinsic Motivation Inventory with four subscales $(\mathrm{N}=118)$ 


\section{Discussion}

Firstly, we hypothesized a positive effect of students' choice on intrinsic motivation. Our study results support our hypothesis. Findings on the effects of choice on autonomy (and motivation) are ambiguous in the literature. For example, Katz and Assor (2007) reported positive, negative or no effects of choice in a range of studies. Patall et al. (2008) conducted a meta-analysis, and concluded that choice might have positive effects on autonomy, given certain circumstances, i.e. the options and the number of options (see also Iyengar \& Lepper, 2000) need to be adequate and, in particular, the surveillance and the attendance of the students need to be appropriately controlled. The options should not conflict with the attitudes of the students or their parents. Furthermore, at least one of the options should be interesting so as to make the process attractive and meaningful to the students (Meyer-Ahrens \& Wilde, 2013). These are prerequisites for a meaningful choice and an effective impact on the students' autonomy. We assume that the positive effect on intrinsic motivation found in the current study was strongly dependent on the students' perception of autonomy and the operationalization of the vote. This context appears to be appropriate for eleven year-olds: four options, including interesting options; an explanation of the selection process; transparency of the procedure; a report of the outcome in the same lesson; a caring attitude by the teacher towards the students. Presumably, the basic needs were incorporated appropriately in the selection process and in the subsequent lessons. In addition, it appears that the students were affected positively by the choice of their topic, and their perceived autonomy.

Secondly, we were interested in knowing if the process of choosing alone might influence motivation, or if only a fulfilled choice had a positive effect. The comparison of the two main conditions, i.e. "choice received" and "choice not received" led to an unexpected result when compared to previous research (Folger et al., 1979; Baldwin et al., 1991). We found no difference in motivation between the groups. Unlike in most other studies, the difference between choice and no choice cannot entirely be attributed to the congruence of the chosen topic and individual interests (Katz \& Assor, 2007; Patall et al., 2008). The students who voted for their topic, but didn't receive their choice, reported the same level of motivation as those students who received their choice. Their higher motivation seems attributable to the voting process itself. Further, no frustration was found when choice was not realized. The students who participated in the voting process showed no significant differences with regard to their perceived competence, perceived choice and perceived pressure during the lessons. Despite the fact that not all the students were taught their chosen topic, the group as a whole seemed to perceive the selection process as self-determined. This suggests that the lesson might have been experienced as „commonly determined”. The pupils understood that in a democratic vote not all wishes can be satisfied. Therefore, we assume that the individuals' locus of causality and volition (Reeve, 2002) did not suffer when not receiving their choice. A caring and appreciative attitude towards the pupils, as well as openness and transparency in the choosing process (see also Patall et al., 2008) might have prepared the pupils who did not receive their choice to fully accept the results of the vote. They may have felt connec-ted to their fellow pupils (Deci \& Ryan, 2002) and feeling a part of the class may have led them to embrace the group decision as their own. Consequently, all pupils of the choice treatment perceived autonomy and intrinsic motivation.

\section{References}

Assor, A., Kaplan, H., \& Roth, G. (2002). Choice is good, but relevance is excellent: Autonomyenhancing and suppressing teacher behaviours predicting students' engagement in schoolwork. British Journal of Educational Psychology, 72(2), 261-278.

Baldwin, T., Magjuka, R., \& Loher, B. (1991). The perils of participation: Effects of choice of training on trainee motivation and learning. Personnel Psychology, 44(1), 51-65. 
Deci, E. L. \& Ryan, R. M. (1985). Intrinsic motivation and self-determination in human behavior.New York: Plenum. Deci, E. L., \& Ryan, R. M. (2000). The "what" and "why" of goal pursuits: Human needs and the self-determination of behavior. Psychological Inquiry, 11, 227-268.

Deci, E. L. \& Ryan, R. M. (2002). Self-determination research: Reflections and future directions. In E. L. Deci \& R. M. Ryan (Eds.), Handbook of self-determination research (pp. 431-441). Rochester: University of Rochester Press.

Deci, E. L., \& Ryan, R. M. (2010). Intrinsic Motivation Inventory (IMI). Retrieved December 21, 2010, from Web site:http://www.psych.rochester.edu/SDT/ measures/IMI_scales.php

Folger, R., Rosenfield, D., Grove, J., \& Corkran, L. (1979). Effects of 'voice' and peer opinions on responses to inequity. Journal of Personality and Social Psychology, 37, 2253- 2261.

Iyengar, S. S. \& Lepper, M. R. (2000). When choice is demotivating: Can one desire too much of a good thing? Journal of Personality and Social Psychology, 79 (6), 995-1006.

Katz, I., \& Assor, A. (2007). When Choice Motivates and When It Does Not. Educational Psychology Review, 19(4), 429-442.

Krapp, A. \& Ryan, R. (2002). Selbstwirksamkeit und Lernmotivation. Eine kritische Betrachtung der Theorie von Bandura aus Sicht der Selbstbestimmungstheorie und der pädagogischpsychologischen Interessentheorie. Zeitschrift für Pädagogik. Selbstwirksamkeit und Motivationsprozesse in Bildungsinstitutionen. 44,. 54-82.

Löwe, B. (1992). Biologieunterricht und Schülerinteresse an Biologie. Weinheim: Deutscher Studien Verlag.

Meyer-Ahrens, I., \& Wilde, M. (2013). Der Einfluss von Schülerwahl und der Interessantheit des Unterrichtsgegenstandes auf die Lernmotivation im Biologieunterricht. Unterrichtswissenschaft, 41(1), 57-71.

Patall, E. A., Cooper, H., \& Robinson, J.C. (2008). The Effects of Choice on Intrinsic Motivation and Related Outcomes: A Meta-Analysis of Research Findings. Psychological Bulletin, 134 (2), $270-300$.

Reeve, J. (2002). Self-determination theory applied to educational settings. In E. L. Deci \& R. M. Ryan (Eds.), Handbook of self-determination research (pp. 184-203). Rochester: University of Rochester Press.

Reeve, J., Nix, G., \& Hamm, D. (2003). The experience of self-determination in intrinsic motivation and the conundrum of choice. Journal of Educational Psychology, 95, 375-392.

Reynolds, P. L., \& Symons, S. (2001). Motivational variables and children's text search. Journal of Educational Psychology, 93, 14-22.

Ryan, R.M. \& Deci, E.L. (2006). Self-Regulation and the Problem of Human Autonomy: Does Psychology Need Choice, Self-Determination, and Will? Journal of Personality, 74(6), 15571586.

Wilde, M., Bätz, K., Kovaleva, A., \& Urhahne, D. (2009). Überprüfung einer Kurzskala intrinsischer Motivation (KIM). Zeitschrift für Didaktik der Naturwissenschaften, 15, 31-45. 